\title{
Determinan Nilai Indeks Prestasi Akademik Mahasiswa Pendidikan Agama Islam
}

Darwis $^{1^{*}}$

${ }^{1}$ STAIN Majene, Indonesia

*Korespondensi: darwis@stainmajene.ac.id

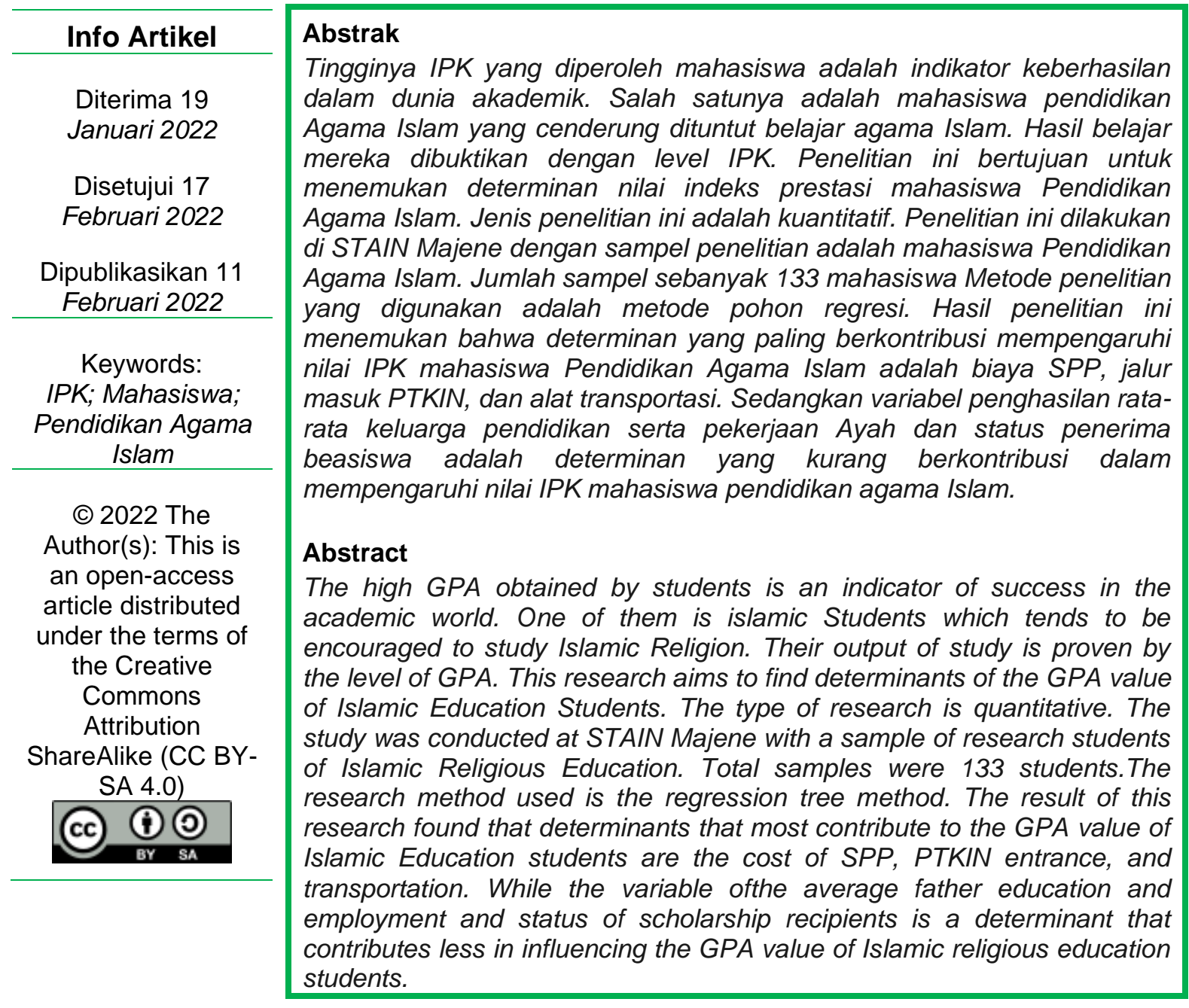

\section{Pendahuluan}

Students are agents of change yang menjadi inisiator masa depan menuju era industri 5.0 (Predy et al., 2019). Selain itu, mahasiswa punya peranan penting dalam perkembangan ilmu pengetahuan pada dunia kampus yang dimiliki sesuai perkembangan zaman di mana harus mampu bersaing baik dalam bidang nasional 
maupun internasonal. Pada era milineal sekarang ini, para mahasiswa selain fokus menimbah ilmu pada bangku kuliah, ada hal lain yang mereka miliki yaitu bakat dan skill yang mampu menjadikan kampus lebih berkembang kedepannya.

Para mahasiswa setelah lulus harus mulai memikirkan apa yang akan dilakukan karena kesuksesan dan prestasi mahasiswa selama kuliah setelah lulus merupakan salah satu indikator keberhasilan program studi. Selain itu, adanya pergantian instrumen kriteria standar 7 menjadi kriteria standar 9 untuk akreditasi program studi mendorong mahasiswa harus berhasil dalam kegiatan akademik. Kriteria standar 9 ini pada bagian bidang mahasiswa lebih memperhatikan publikasi ilmiah, karya, dan prestasi mahasiswa (Junaidah \& Ayu, 2019). Beberapa tantangan lain yang ditemukan pada beberapa kampus yang terbilang usianya masih dini sudah harus bersiap diri untuk menghadapi persaingan yang cukup ketat. Salah satu kampus yang tergolong masih baru yaitu Perguruan Tinggi Keagamaan Islam Negeri (PTKIN) STAIN Majene yang berlokasi pada provinsi Sulawesi Barat kabupaten Majene, maka kondisi tersebut perlu sumber daya manusia yang unggul terkhusus bagi mahasiswa yang harus memiliki banyak prestasi dibidangnya agar bisa bersaing dengan kampus ternama di Indonesia.

Prestasi akademik menjadi keberhasilan yang memiliki tingkatan khusus karena belajar dari beberapa tugas, atau tingkatan lain yang dimiliki seperti keahlian/kecakapan pada beberapa tugas di sekolah dan akademis. Indeks prestasi akademik adalah salah satu prestasi awal untuk menilai pencapaian mahasiswa. Tidak bisa dipungkiri, penilaian akreditasi pun melihat indeks prestasi mahasiswa. Pengertian prestasi secara akademis atau pendidikan merupakan satu tingkatan khusus perolehan melalui beberapa tes yang sudah dibakukan dan guruguru menilai hasil keahlian dalam berkarya pada bidang akademis atau hasil keahlian atau gabungan dari kedua kondisi tersebut (Chaplin, 2006). Di samping itu, terdapat faktor luar yang dapat memengaruhi perbedaan prestasi belajar pada diri siswa sebagaimana dijelaskan oleh beberapa penelitian sebelumnya (Hanifah \& Abdullah, 2017; Karyanus et al., 2013; Setyawati et al., 2020; Sihite \& Pratiwi, 2018; Tampil et al., 2017) yaitu:

(a) Sarana dan prasarana belajar, tepat waktu sekolah, proses belajar di lingkungan sekolah, dan pengelompokan mahasiswa,

(b) Aturan sekolah, keadaan sosial siswa, hubungan interaksi mahasiswa dengan dosen dan mahasiswa dengan mahasiswa,

(c) Politik waktu dan tempat dan situasional.

Sedangkan ada dua faktor internal yang memengaruhi perbedaan prestasi belajar pada diri siswa yaitu:

(a) Fisiologis, perkembangan karakter perilaku, kesehatan jasmani, tampak percaya diri, biological individuality.

(b) Psikologi, kemauan belajar, karakter, semangat belajar, dan intelligence, kepekaaan, budaya, keadaan status sosial, dan ekonomi.

IPK (indeks Prestasi Kumulatif) salah satu indikator prestasi yang dimiliki mahasiswa yang mengukur pada bidang akademik. Kualitas nilai IPK memiliki beberapa pengaruh besar terhadap para pengajar yg mumpuni dibidangnya, penguasan bahan materi, metode yang dilakukan ketika mengajar, dan 
penggunaan media pembelajaran. Kebiasaan dan perilaku belajar adalah faktor yang mempengaruhi IPK mahasiswa(Hanifah \& Abdullah, 2017). Di samping itu, faktor manajemen diri, lingkungan, dan kesehatan juga mempengaruhi nilai indeks prestasi mahasiswa (Hendikawati, 2011a, 2011b). Hal yang sama dijelaskan dijelaskan oleh peneliti lain bahwa menjadi dasar indikator keberhasilan prestasi seorang mahasiswa pada bidang akademik yang dapat dilihat yaitu nilai IPK setiap semester dan diakhir berakhirnya studi (Muhibbin, 2007). IPK bisa dapat diperoleh dari hasil tugas-tugas yang diberikan oleh pengajar yang selesai dikerjakan sesuai waktu yang ditentukan.

Di samping itu, kedisiplinan mahasiswa selama perkuliahan, nilai ujian, dan keaktifan menjadi bahan penilaian pengajar bagi perolehan Indeks prestasi mahasiswa. Jadi IPK salah satu indikator keberhasilan mahasiswa pada bidang akademik. Ada beberapa penelitian pernah mengkaji tentang prestasi mahasiswa di antaranya (Retnowati et al., 2016) tentang motivasi dan akademik prestasi mahasiswa sarjana program studi pendidikan geografi di Universitas Malang, faktor-faktor prestasi akademik mahasiswa pada program studi akuntansi di Universitas Semarang (Indriana et al., 2017). Hasil yang sama, terjadi hubungan positif antara prestasi akademik dengan motivasi berprestasi pada mahasiswa fakultas psikologi di Universitas Prima Indonesia (Siregar, 2017).

Dari beberapa penelitian yang mengkaji tentang itu, pada penelitian ini, akan mengkaji lebih lanjut tentang faktor- faktor variabel yang berpengaruh terhadap nilai IPK mahasiswa pada program studi pendidikan agama Islam STAIN Majene. Dengan adanya penelitian ini, diharapkan kampus STAIN Majene agar dapat bersaing pula baik bidang nasional maupun intenasional dan menjadi solusi bagi kebijakan kampus untuk memperbaiki bersama agar mecapai misi menjadi kampus yang unggul dan malaqbiq. PAI saat ini adalah satu-satunya program studi yang memiliki akreditasi B di STAIN Majene. Tingkat IPK rata-rata di atas 3.5. Oleh karena itu, program studi tersebut menarik untuk diteliti. Adapun tujuan penelitian ini adalah untuk menemukan faktor-faktor variabel mempengaruhi terhadap prestasi akademik Mahasiswa prodi PAI STAIN Majene.Kontribusi teoritis adalah untuk memberikan penjelasan dan pemahaman secara empiris mengenai faktorfaktor dalam memengaruhi prestasi akademik mahasiswa. Di samping itu, penelitian ini mengidentifikasi faktor tersebut melalui metode pohon regersi yang menjadi kebaharuan penelitian ini dibandingkan penelitian lain.

\section{Metode Penelitian}

Jenis penelitian ini adalah kuantitatif. Lokasi penelitian ini dilakukan di STAIN Majene. Penelitian ini menggunakan data sekunder. Data tersebut berupa data mahasiswa prodi PAI Angkatan 2018 STAIN Majene. Hasil data tersebut diperoleh dari data SIAKAD STAIN Majene. Jumlah sampel dalam penelitian ini adalah 133 mahasiswa. Sampel tersebut kemudian dianalisis secara statistik deskrptif. Setelah itu, analisis data menggunakan metode pohon regresi. Metode penelitian tersebut memberikan kaidah keputusan yang paling berpengaruh di antara semua variabel yang ditetapkan dalam penelitian (Lewis et al., 2000; Loh, 2011; Rao, 2013). Dalam metode tersebut, diperlukan variabel terikat dan variabel bebas. Variabel terikat $(y)$ yang diamati dalam penelitian ini adalah Nilai Indeks Prestasi Akademik (IPK), sedangkan variabel bebas yang di gunakan adalah 


$$
\begin{aligned}
& \boldsymbol{x}_{1}=\text { Jalur Masuk PTKIN), } \\
& \boldsymbol{x}_{2}=\text { Status Penerima Beasiswa, } \\
& \boldsymbol{x}_{3}=\text { Biaya SPP, } \\
& \boldsymbol{x}_{\mathbf{4}}=\text { Alat Transportasi, } \\
& \boldsymbol{x}_{5}=\text { Pendidikan Ayah, } \\
& \boldsymbol{x}_{6}=\text { Pekerjaan Ayah, } \\
& \boldsymbol{x}_{7}=\text { Penghasilan Orang Tua }
\end{aligned}
$$

\begin{tabular}{|c|c|}
\hline Jalur Masuk PTKIN & $\begin{array}{l}\text { Kode } 1 \text { SPAN } \\
\text { Kode } 2 \text { UM-PTKIN } \\
\text { Kode } 3 \text { UMM }\end{array}$ \\
\hline Status Penerima Beasiswa & $\begin{array}{l}\text { Kode } 1 \text { Tidak Terima } \\
\text { Kode } 2 \text { Terima }\end{array}$ \\
\hline Biaya SPP & $\begin{array}{l}\text { Kategori } 1 \text { Rp } 400.000, \\
\text { Kategori } 2 \text { Rp 800.000, } \\
\text { Kategori } 3 \text { Rp 1.100.000, } \\
\text { Kategori } 4 \text { Bidik Misi }\end{array}$ \\
\hline Alat Transportasi & $\begin{array}{l}\text { Kode } 1 \text { Tidak ada } \\
\text { Kode } 2 \text { Ojek/Angkutan/Sepeda Motor } \\
\text { Kode } 3 \text { Jalan Kaki } \\
\text { Kode } 4 \text { Lain-lain }\end{array}$ \\
\hline Pendidikan Ayah & $\begin{array}{l}\text { Kode } 1 \text { Tidak Berpendidikan normal } \\
\text { Kode } 2 \text { SD/SMP/SMA/Diploma } \\
\text { Kode } 3 \text { S1/S2/S3 }\end{array}$ \\
\hline Pekerjaan Ayah & $\begin{array}{l}\text { Kode } 1 \text { Guru/Dosen/pns/Pegawai } \\
\text { swasta } \\
\text { Kode } 2 \text { Petani/Peternak/ Pedagang/ } \\
\text { Nelayan/Buruh tani/ Pabrik bangunan } \\
\text { Kode } 3 \text { Tidak bekerja/pensiunan/ } \\
\text { Almarhum } \\
\text { Kode 4 Lainnya }\end{array}$ \\
\hline Penghasilan rata-rata orang tua & $\begin{array}{l}\text { Kode } 1 \text { di bawah Rp } 1.000 .000 \\
\text { Kode } 2 \text { Rp } 1.000 .000-\operatorname{Rp} 2.000 .000 \\
\text { Kode } 3 \operatorname{Rp} 2.000 .000-\operatorname{Rp} 4.000 .000\end{array}$ \\
\hline
\end{tabular}

Adapun penjelasan dari variabel-variabel di atas adalah sebagai berikut. 


\section{Kode 4 Rp 4.000.000-Rp 6.000.000}

\section{Hasil dan Pembahasan}

\subsection{Deksripsi Data}

Deskripsi Data Mahasiswa Program Studi PAI Angkatan 2018 berdasarkan data SIAKAD STAIN Majene berjumlah 133 orang. Variabel bebas dalam penelitian ini terdiri dari tujuh variabel $\boldsymbol{x}_{1}=$ Jalur Masuk PTKIN, $\boldsymbol{x}_{2}=$ Status Penerima Beasiswa, $\quad \boldsymbol{x}_{\mathbf{3}}=$ Biaya SPP, $\boldsymbol{x}_{\mathbf{4}}=$ Alat Transportasi, $\boldsymbol{x}_{5}=$ Pendidikan Ayah, $\boldsymbol{x}_{6}=$ Pekerjaan Ayah, $\boldsymbol{x}_{7}=$ Penghasilan Orang Tua. Deskripsi pertama adalah variabel Jalur Masuk PTKIN. Berikut persentasi variabel bebas dalam bentuk diagram.

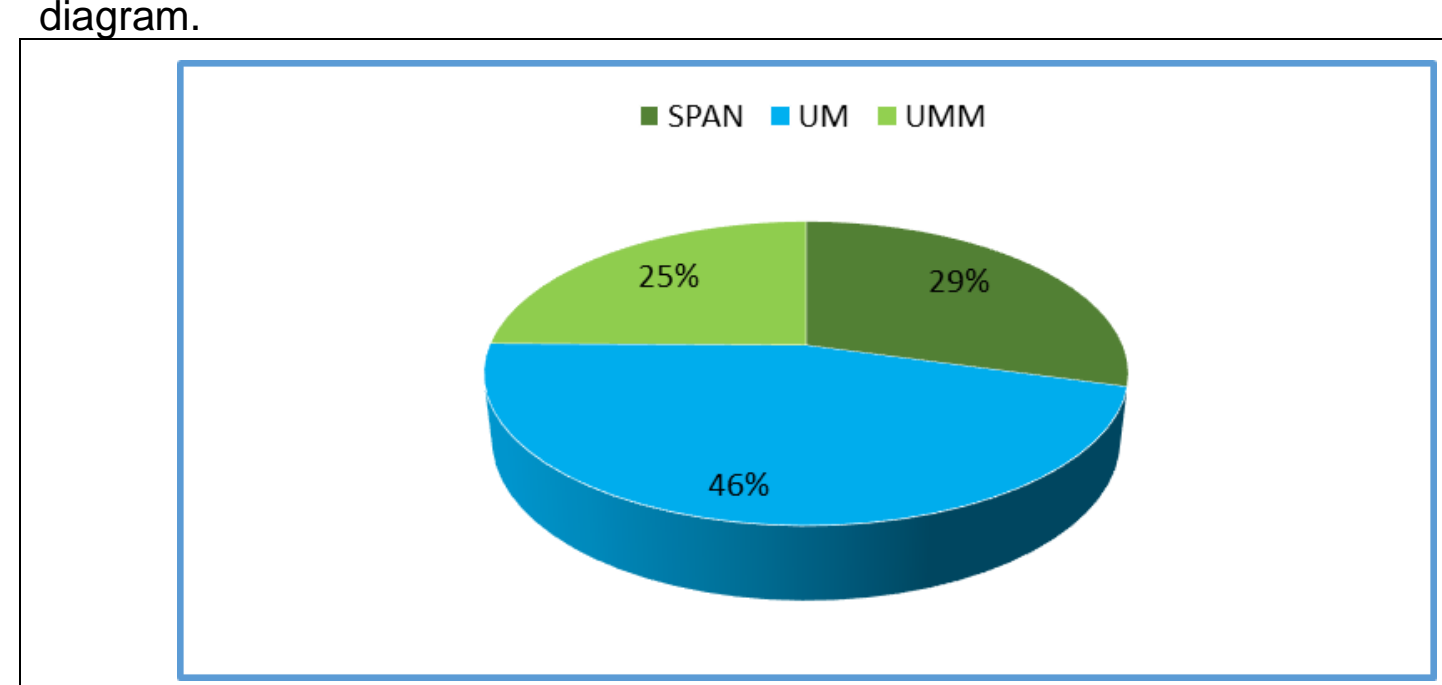

Gambar 1. Presentasi Jalur Masuk PTKIN

Berdasarkan gambar 1 mengenai variabel Jalur Masuk PTKIN, diagram lingkaran sebanyak 25\% Mahasiswa diterima melalui jalur UMM, sebanyak 29\% mahasiswa yang diterima melalui jalur SPAN, dan 46\% mahasiswa yang diterima melalui jalur UM-PTKIN. Hasil ini menunjukkan bahwa mahasiswa Pendidikan Agama Islam di STAIN Majene lebih banyak masuk jalur PTKIN sebanyak 46\% dari keseluruhan.

Diagram lingkaran selanjutnya yaitu variabel Status Penerima Beasiswa. Gambar 2 sebagai berikut.

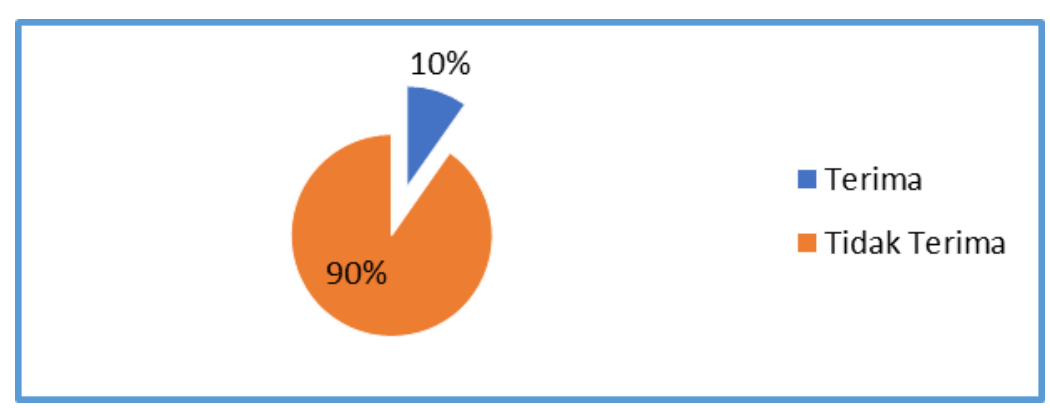

Gambar 2. Presentasi Status Penerima Beasiswa

Berdasarkan gambar diagram lingkaran di atas sebanyak 90\% Mahasiswa tidak menerima beasiswa, dan $10 \%$ mahasiswa yang menerima beasiswa prodi PAI mahasiswa angkatan 2018. Hasil ini menunjukkan bahwa hanya $10 \%$ 
mahasiswa Pendidikan Agama Islam di STAIN Majene memeroleh beasiswa. Sisanya sebesar $90 \%$ adalah biaya sendiri dari keluarga.

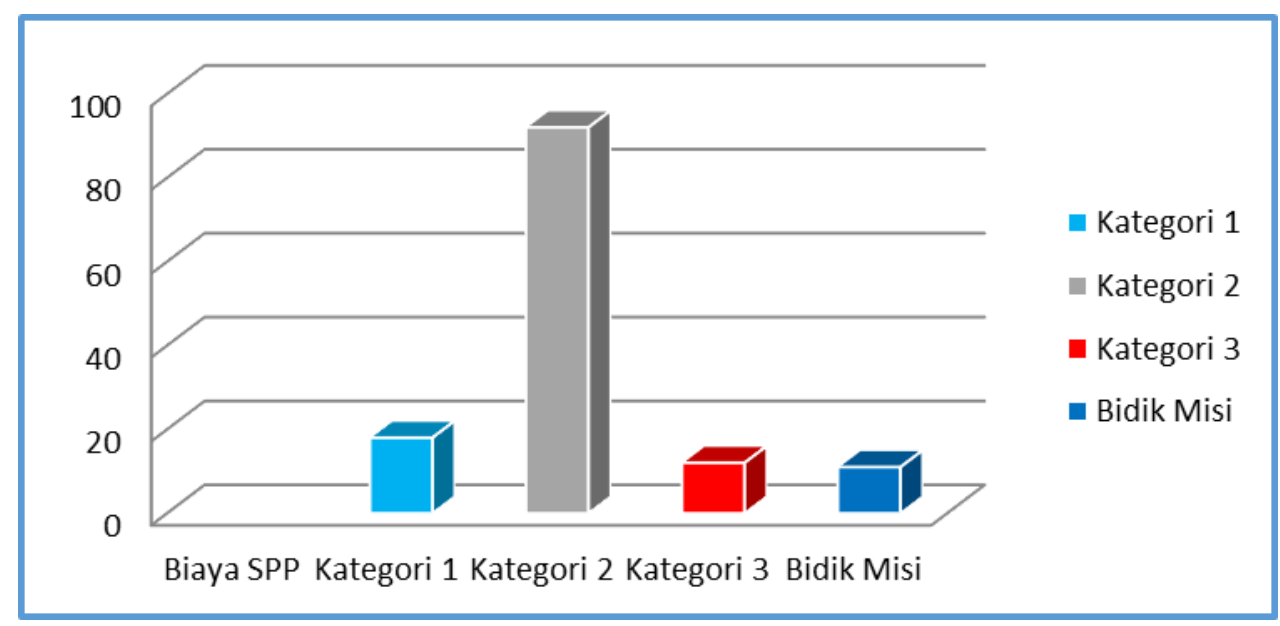

Gambar 3. Biaya SPP

Pada gambar 3 menunjukkan diagram batang. Berdasarkan gambar diagram batang sebanyak mahasiswa dapat kategori 1 berjumlah 18 orang, kategori 2 berjumlah 92 orang, kategori 3 berjumlah 12 orang dan yang menerima beasiswa Bidik Misi berjumlah 11 orang. Hasil ini menunjukkan bahwa 10\% dari total mahasiswa yang memperoleh beasiswa bidik misi. Sementara kategori 2 berjumlah paling tinggi.

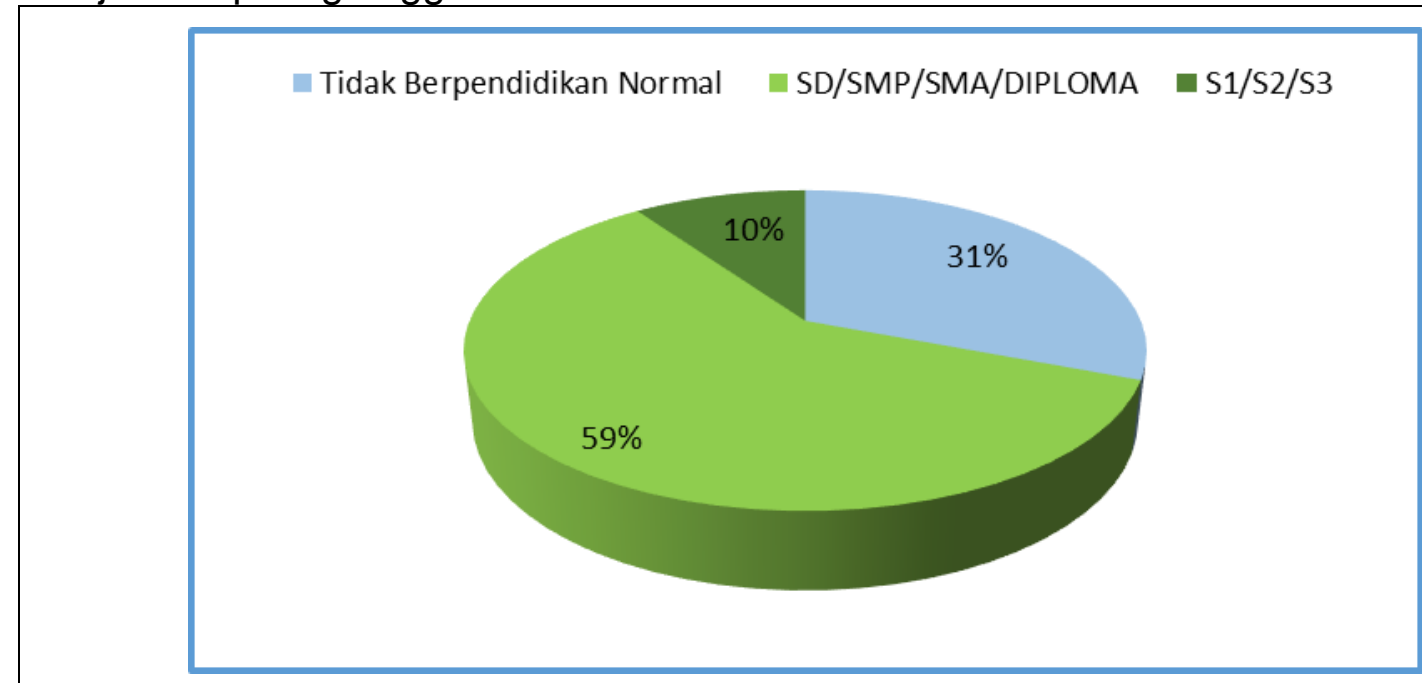

Gambar 4. Pendidikan Ayah

Pada gambar 4 menunjukkan variabel pendidikan Ayah dengan menggunakan diagram lingkaran. Berdasarkan gambar diagram lingkaran sebanyak 59\% Ayahnya Tidak Berpendidikan Normal, dan 31\% Ayahnya SD/SMP/SMA/Diploma dan Ayahnya 10\% S1/S2/S3 mahasiswa prodi PAI mahasiswa angkatan 2018. Hasil ini menunjukkan bahwa mahasiswa prodi Pendidikan Agama Islam tidak memiliki latar pendidikan Ayah lebih tinggi sebesar 59\% dibandingkan yang berpendidikan. Sangat rendah mahasiswa pendidikan agama Islam yang memiliki latar pendidikan ayahnya Sarjana. tersebut.

Selanjutnya variabel pekerjaan Ayah. Gambar 5 menunjukkan variabel 


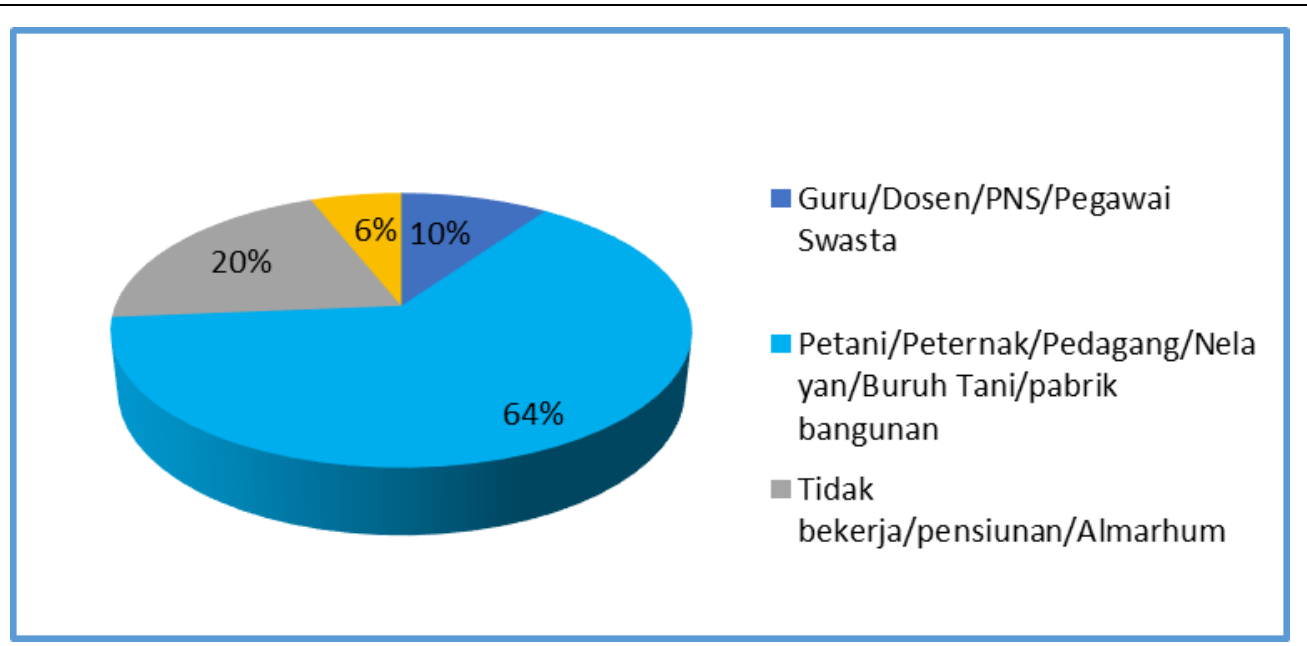

Gambar 5. Pekerjaan Ayah

Berdasarkan gambar diagram lingkaran sebanyak $6 \%$ pekerjaan lain-lain, dan $10 \%$ pekerjaan Ayahnya petani/peternak/pedagang/nelayan/buruh tani/pabrik bangunan dan Ayahnya 64\% tidak bekerja/pensiunan/almarhum dan $20 \%$ pekerjaan Ayahnya Guru/Dosen/Pegawai Swasta mahassiswa prodi PAI mahasiswa angkatan 2018. Hasil ini menunjukkan bahwa sebagian besar sebanyak 64\% mahasiswa pendidikan Agama Islam berasal dari keluarga yang tidak bekerja atau sudah pensiun. Sementara hanya sedikit berasal dari keluarga petani/peternak/pedagang dan sejenisnya.

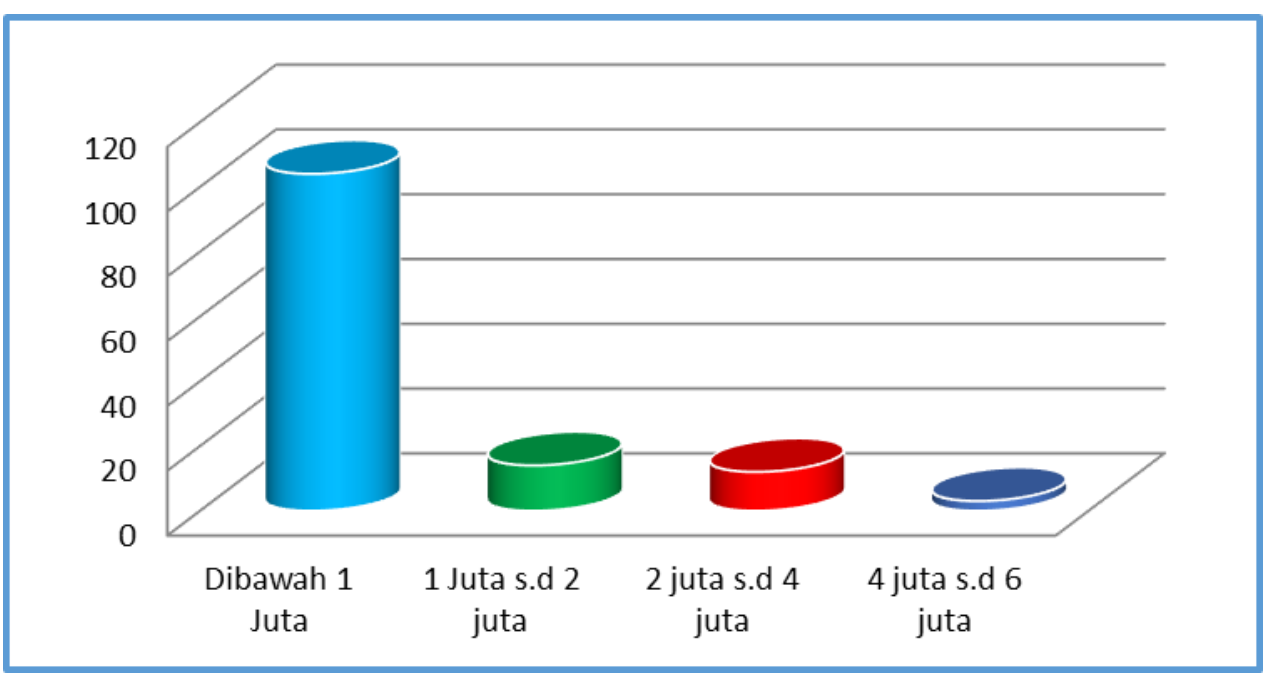

Gambar 6. Penghasilan rata-rata orang tua

Variabel selanjutnya adalah Penghasilan rat-rata orang tua. Berdasarkan gambar diagram batang sebanyak Mahasiswa yang penghasilan rata-rata orang tua dibawah 1 juta berjumlah 104 orang, 1 juta s.d 2 juta berjumlah 14 orang, 2 juta s.d 4 juta berjumlah 12 orang dan 4 juta s.d 6 juta berjumlah 3 orang. Hasil diagram batang ini menunjukkan bahwa sebagian besar (100 mahasiswa) memiliki rata-rata penghasilan orang tuanya di bawah 1 juta rupiah. 


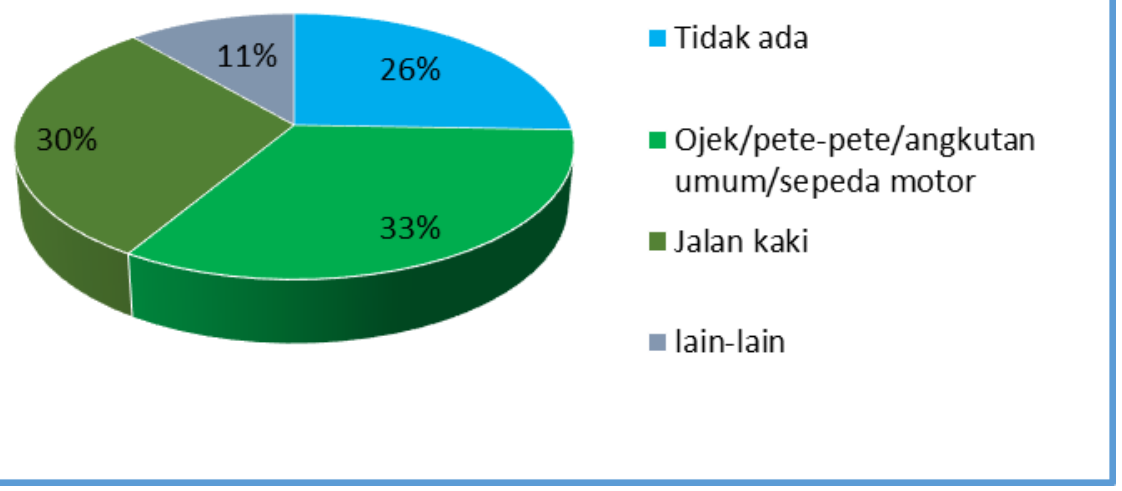

Gambar 7. Alat transportasi

Variabel selanjutnya adalah Alat Transportasi. Berdasarkan gambar diagram lingkaran sebanyak $11 \%$ alat transportasi ke kampus lain-lain sebesar $11 \%$,dan $26 \%$ alat transportasinya tidak ada dan 30\% jalan kaki ke kampus dan 33\% menggunakan ojek/pete-pete/angkutan umum/sepeda motor ke kampus. Alat transportasi sangat menunjang kegiatan akademik mahasiswa. Dalam penelitian ini, sebagian besar mahasiswa Pendidikan Agama Islam menggunakan kendaraan baik itu ojek, pete-pete, angkutan umum, atau sepeda motor. Hasilnya menunjukkan sebesar 33\%. Nilai itu tidak beda jauh dengan 30\% mahasiswa yang jalan kaki ke kampus. Hal ini dikarenakan mereka lebih memilih menetap (kos) disekitar kampus sehingga mereka hanya jalan kaki ke kampus.

\subsection{Pembahasan}

Penelitian ini menggunakan metode regresi pohon. Adapun variabel bebas adalah Jalur Masuk PTKIN, Status Penerima Mahasiswa, Kategori Biaya SPP, Alat Transportasi, Pendidikan Ayah, Pekerjaan Ayah dan Penghasilan Orang Tua, sedangkan variabel terikatnya adalah indeks prestasi Akademik. Hasil data berdasarkan variabel-variabel yang berpengaruh sebagai variabel bebas yang membentuk suatu simpul. 


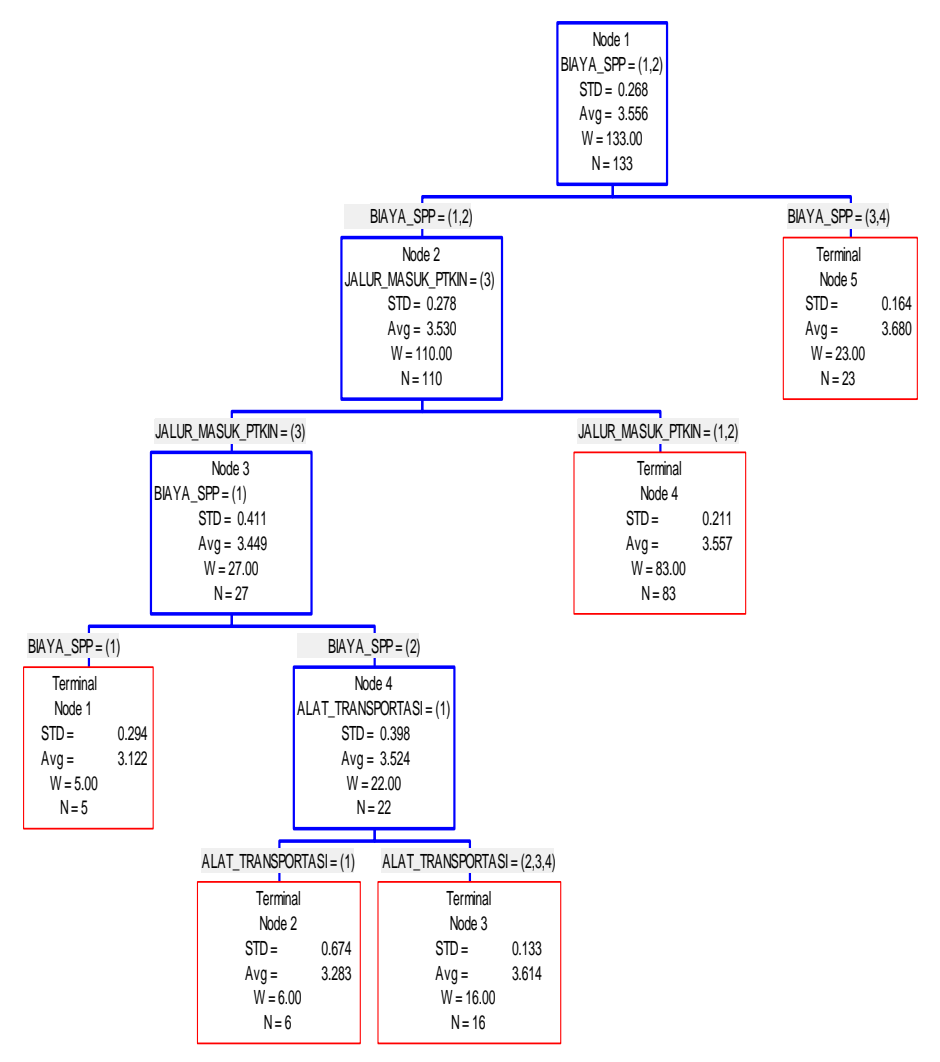

Gambar 8. Pohon optimum nilai IPK

Metode pohon regresi menghasilkan beberapa ranting pertama hingga ranting terakhir. Variabel yang paling berpengaruh akan menjadi simpul pertama yang dihasilkan. Berdasarkan gambar 8, variabel Biaya SPP Mahasiswa merupakan variabel yang paling berpengaruh terhadap nilai prestasi akademik mahasiswa Program Studi PAI Angkatan 2018 STAIN Majene. Sehingga variabel Biaya SPP menjadi simpul pertama yang dihasilkan. Dari tujuh variabel yang digunakan, ada tiga variabel yang muncul pada pohon regresi, yaitu rata-rata biaya SPP, alat transportasi dan jalur masuk PTKIN. Ketiga variabel inilah yang dianggap memiliki pengaruh terhadap variabel bebas yaitu indeks prestasi akademik mahasiswa pendidikan agama Islam.

Selanjutnya, berdasarkan aturan Cost Complexity Minimum dan penggunaan validasi silang lipat 10 (10-fold cross validation) diperoleh pohon optimum seperti pada Gambar 9. Pohon ini mengandung lima buah simpul terminal. Variabel terikat yang menyekat adalah biaya SPP, jalur masuk PTKIN, dan alat transportasi selama menempuh pendidikan. Hal ini menandakan bahwa peubah penjelas biaya SPP, jalur masuk PTKIN, dan alat transportasi mahasiswa mempunyai tingkat keragaman paling tinggi dalam menjelaskan tingkat kunci keberhasilan nilai IPK mahasiswa. 


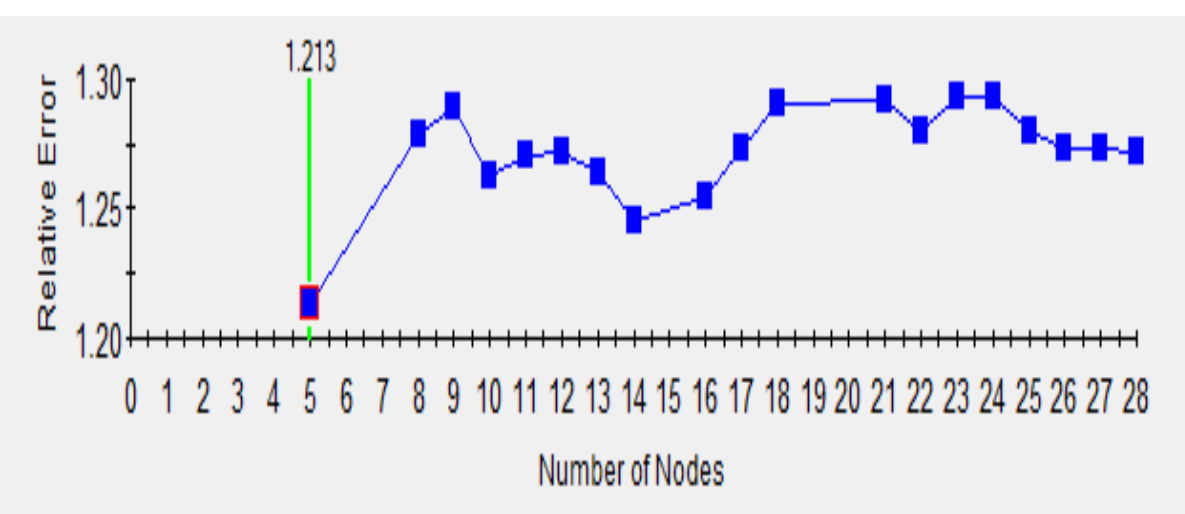

Gambar 9. Plot $\mathrm{R}^{\mathrm{cv}}$ (x-val Relative Error)

Analisis berikutnya adalah pengelompokan mahasiswa berdasarkan level nilai IPK yang diperolehnya sebagaimana disajikan pada Tabel 1.

Tabel 1. Karakteristik kelompok nilai IPK Mahasiswa Prodi PAI STAIN Majene

\begin{tabular}{|c|c|c|c|}
\hline Grup & $\mathbf{N}$ & Prediksi Nilai IPK & Variabel Bebas \\
\hline 1 & 5 & 3.12 & Biaya SPP Kode 1 (Rp 400.000,-) \\
\hline 2 & 23 & 3.68 & $\begin{array}{l}\text { Kode } 3 \text { Biaya SPP (Rp 1.100.000, } \\
\text { dan kode } 4 \text { Beasiswa/Bidik Misi }\end{array}$ \\
\hline 3 & 6 & 3.28 & Kode 1 Alat Transportasi-Tidak ada \\
\hline 4 & 16 & 3.61 & $\begin{array}{l}\text { Kode } 2 \text { Alat Transportasi-Sepeda } \\
\text { Motor, } \\
\text { Kode } 3 \text { Ojek/angkutan umum/ } \\
\text { bus/pete-pete, } \\
\text { Kode } 4 \text { lain-lain/jalan kaki(4) }\end{array}$ \\
\hline 5 & 83 & 3.56 & $\begin{array}{l}\text { Jalur Masuk PTKIN } \\
\text { Kode } 1 \text { SPAN } \\
\text { Kode } 2 \text { UM-PTKIN }\end{array}$ \\
\hline
\end{tabular}

Analisis pertama pada pengelompokan nilai IPK yang paling tinggi. Pada Mahasiswa yang Biaya SPP (Kode 3 Rp 1.000.000 dan Kode 4 Beasiswa Bidik Misi mempunyai dugaan nilai IPK lebih tinggi yaitu sebesar 3.68 sedangkan Mahasiswa Biaya SPP Kode 1 (Rp 400.000,-) mempunyai prediksi nilai IPK sebesar 3.12. Hal ini bisa disebabkan karena mahasiswa yang biaya SPP tergolong tinggi ada dukungan finansial untuk mereka dan sungguh-sungguh belajar apalagi yang dapat beasiswa Bidik Misi. Dengan kata lain, hasil ini dapat dijelaskan bahwa beasiswa menjadi faktor bagi mahasiswa untuk terus meningkatkan nilai IPK. Terlebih lagi, ada syarat yaitu IPK yang harus dipenuhi jika mereka lanjut mendapatkan beasiswa bidik misi sehingga mahasiswa dengan beassiwa bidik misi mampu memengaruhi level IPK. Dengan demikian, peubah yang paling dominan mempengaruhi nilai IPK Mahasiswa adalah Biaya SPP.

Peubah yang muncul setelah variabel biaya SPP yaitu variabel Alat Transportasi dan Jalur Masuk PTKIN. Untuk Mahasiswa Alat Transportasi (Kode 2 Sepeda Motor, Kode 3 Ojek/angkutan umum/bus/pete-pete, Kode 4 lain-lain/jalan kaki) mempunyai dugaan nilai IPK lebih tinggi yaitu sebesar 3.61 sedangkan 
Mahasiswa Alat Transportasi (Kode 1 Tidak ada) mempunyai prediksi nilai IPK 3.28. Hasil ini dapat dijelaskan bahwa IPK yang lebih tinggi dipengaruhi cara mahasiswa menuju ke kampus. Mahasiswa yang difasilitasi orang tuanya dengan alat transportasi cenderung memiliki IPK yang lebih rendah. Sementara mahasiswa yang tidak difasilitasi alat kendaraan IPKnya jauh lebih tinggi.

Selanjutnya Mahasiswa Jalur Masuk PTKIN (Kode 1 SPAN, Kode 2 UM) mempunyai prediksi nilai IPK 3.56. Jumlah mahasiswa diperoleh pada jalur masuk PTKIN 83 orang sebagaimana pada Tabel 1. Ini berarti bahwa sebagian besar mahasiswa pendidikan Agama Islam dengan Jalur SPAN dan UM memiliki nilai IPK yang tinggi sebesar 3.56.

\section{Kesimpulan}

Metode pohon regresi berhasil digunakan untuk memberikan keputusan terhadap variabel yang paling dominan atau berkontribusi dalam memengaruhi variabel terikat yaitu indeks prestasi akademik. Adapun hasilnya adalah bahwa variabel bebas yang paling dominan dalam memengaruhi variabel terikat yaitu nilai IPK Mahasiswa Program Studi Pendidikan Agama Islam STAIN Majene adalah variabel biaya SPP, variabel jalur masuk PTKIN, dan variabel Alat Transportasi. Faktor-faktor variabel yang kurang berkontribusi dari hasil penelitian terhadap kunci keberhasilan nilai prestasi akademik Mahasiswa Program Studi Pendidikan Agama Islam adalah Penghasilan rata-rata Ayah, Pendidikan, pekerjaan dan status penerima beasiswa.

Saran praktis dalam penelitian ini adalah ditujukan kepada lembaga pendidikan Agama.bahwa diperlukan perhatian lebih untuk variabel-variabel yang memiliki pengaruh dominan yang terdiri dari variabel biaya SPP, jalur masuk PTKIN, dan alat transportasi.Penelitian ini juga mengungkapkan bahwa mahasiswa Prodi Pendidikan Agama Islam di STAIN Majene sebagian besar berasal dari keluarga yang kurang mampu dengan latar belakang pendidikan orang tua yang rendah. Di samping itu, hasil deskripsi juga menemukan bahwa mahasiswa tanpa fasilitas alat transportasi memiliki IPK yang jauh lebih tinggi dibanding yang difasilitasi alat transportasi berupa kendaraan. Oleh karena itu, penelitian ini tentu sangat berimplikasi bagi kampus khususnya STAIN Majene bahwa dengan adanya penelitian ini, tentu memberikan gambaran mengenai karakteristik mahasiswa Pendidikan Agama Islam. Di samping saran praktis, penelitian ini memiliki saran bagi peneliti mendatang yang akan menganalisis lebih dalam mengenai topik determinan IPK mahasiswa. Penelitian ini hanya mengidentifikasi determinan dari nilai IPK yang diperoleh mahasiswa Pendidikan Agama Islam. Untuk penelitian lanjutan dalam topik yang samanya, sekiranya mampu menganalisis mahasiswa Pendidikan Agama Islam di beberapa kampus Kementerian Agama sehingga diperoleh tambahan determinan yang baru dalam mempengaruhi nilai IPK mahasiswa Pendidikan Agama Islam.

\section{Ucapan Terima Kasih}

Peneliti mengucapkan terima kasih kepada Pusat Penelitian dan Pengabdian kepada Masyarakat (P3M) STAIN Majene sebab melalui program bantuan Litpadimas Kementerian Agama, penelitian ini bisa terselesaikan dengan baik dan mampu berkontribusi dalam dunia penelitian. 


\section{Daftar Pustaka}

Chaplin, J. . (2006). Kamus Lengkap Psikologi. PT. PT. Raja Grafindo Persada.

Hanifah, \& Abdullah, S. (2017). Pengaruh Perilaku Belajar Terhadap Prestasi Akademik Mahasiswa Akuntansi. Media Riset Akuntansi, Auditing Dan Informasi, 1(3). https://doi.org/10.25105/mraai.v1i3.1767

Hendikawati, P. (2011a). Analisis Faktor yang Mempengaruhi Indeks Prestasi Mahasiswa. Kreano: Jurnal Matematika Kreatif-Inovatif, 2(1), 27-35. https://doi.org/10.15294/kreano.v2i1.1243

Hendikawati, P. (2011b). Studi Komparatif Pengaruh Motivasi, Perilaku Belajar, Self-Efficancy dan Status Kerja Terhadap Prestasi Akademik Antara Mahasiswa Bekerja dan Mahasiswa TidakBekerja. Kreano: Jurnal Matematika Kreatif-Inovatif, 2(1).

Indriana, D., Widowati, A. I., \& Surjawati, S. (2017). Faktor-Faktor Yang Mempengaruhi Prestasi Akademik: Studi Kasus Pada Mahasiswa Program Studi Akuntansi Universitas Semarang. Jurnal Dinamika Sosial Budaya, 18(1). https://doi.org/10.26623/jdsb.v18i1.557

Junaidah, \& Ayu, S. M. (2019). Strategi Kerjasama Perguruan Tinggi Keagamaan Islam Negeri Dalam Meningkatkan Akreditasi Prodi. Al-Idarah: Jurnal Kependidikan Islam, 9(2).

Karyanus, D., Ujian, S., \& Asima, M. (2013). ANALISIS STATISTIK FAKTORFAKTOR YANG MEMPENGARUHI INDEKS PRESTASI MAHASISWA. Saintia Matematika, 1(5).

Lewis, R. J., Ph, D., \& Street, W. C. (2000). An Introduction to Classification and Regression Tree ( CART ) Analysis. 2000 Annual Meeting of the Society for Academic Emergency Medicine, 310.

Loh, W. Y. (2011). Classification and regression trees. Wiley Interdisciplinary Reviews: Data Mining and Knowledge Discovery, 1(1). https://doi.org/10.1002/widm.8

Muhibbin, S. (2007). Psikologi Pendidikan Dengan Pendekatan Baru. PT Remaja Rosdakarya.

Predy, M., Sutarto, J., Prihatin, T., \& Yulianto, A. (2019). Generasi Milenial yang Siap Menghadapi Era Revolusi Digital ( Society 5 . 0 dan Revolusi Industri 4. 0 ) di Bidang Pendidikan Melalui Pengembangan Sumber Daya Manusia.

Rao, V. (2013). Introduction to Classification \& Regression Trees (CART) [online]. In Data Science Central.

Retnowati, D. R., Fatchan, A., \& Astina, K. (2016). Prestasi Akademik Dan Motivasi Berprestasi Mahasiswa S1 Pendidikan Geografi Universitas Negeri Malang. Jurnal Pendidikan: Teori, Penelitian, Dan Pengembangan, 1(3).

Setyawati, D. U., Korida, B. D., \& Febrilia, B. R. A. (2020). Analisis Regresi Logistik Ordinal Faktor-Faktor yang Mempengaruhi IPK Mahasiswa. Jurnal Varian, 3(2), 65-72. https://doi.org/10.30812/varian.v3i2.615

Sihite, D. R. D. B., \& Pratiwi, N. (2018). Analisis Jalur Terhadap Faktor Faktor Yang Mempengaruhi Indeks Prestasi Kumulatif (IPK) Mahasiswa. Jurnal 
Statistika Industri Dan Komputasi, 3(1), 31-39.

Siregar, N. (2017). Hubungan Motivasi Berprestasi Dengan Prestasi Akademik Pada Mahasiswa Fakultas Psikologi Universitas Prima Indonesia. JURNAL DIVERSITA, 3(1). https://doi.org/10.31289/diversita.v3i1.1178

Tampil, Y., Komaliq, H., \& Langi, Y. (2017). Analisis Regresi Logistik Untuk Menentukan Faktor-Faktor Yang Mempengaruhi Indeks Prestasi Kumulatif (IPK) Mahasiswa FMIPA Universitas Sam Ratulangi Manado. D'CARTESIAN, 6(2), 56. https://doi.org/10.35799/dc.6.2.2017.17023 